\title{
The effects of muscle relaxants on auditory evoked potentials in humans*
}

\author{
By Field W. Rickards, Graeme M. Clark, Don S. McMahon \\ and David J. Dewhurst (Melbourne) $\dagger$
}

IN studies on auditory sensory information processing it is frequently assumed that the average evoked potentials from the scalp are produced by neural generators in the cortex. This may not be the case as there is evidence to suggest that at least one component of the auditory evoked response may be myogenic (Bickford et al., I964). Therefore, the present study was undertaken to help determine the extent to which auditory evoked responses are myogenic or neurogenic.

This was done by averaging the auditory evoked potentials to tone bursts before and after the administration of muscle relaxants in patients undergoing routine surgery. Differences between the responses were tested statistically for significance. If the average evoked potential was reduced following the administration of a muscle relaxant it was assumed that the response was myogenic, otherwise it was probably neurogenic and arose from generators in the cortex.

In the visual system it has been shown that most components of the visual evoked response are not affected by muscle relaxants (Domino and Corssen, I964). In the auditory system, however, a study on a patient by Bickford et al., I964, and the work of Prichard et al., I965, on animals have demonstrated that part or all of the auditory evoked response may be myogenic. Therefore, it was considered desirable to examine the effects of muscle relaxants on auditory evoked responses in patients in more detail.

\section{Method}

This study was performed on nine patients undergoing routine surgery. There were six males and three females, and their ages ranged from $\mathbf{I} 7$ to 45 years. The experimental procedure was explained to them, and written permission was obtained. They were all given pethidine hydrochloride (I mg./kg., I.M.I.) as a pre-medication, and two also received promethazine hydrochloride $(12 \cdot 5-25 \mathrm{mg}$., I.M.I.). In four patients anaesthesia was induced with thiopentone sodium (4-6 mg./kg., I.V.I.), and in five

* This study was supported by the Felton Bequest and the Sunshine Foundation.

† From the Child Deafness Research Laboratory, Department of Otolaryngology, University of Melbourne, 3052 Australia. 


\section{Field W. Rickards, et al.}

with propanidid (6-7 mg./kg., I.V.I.). An endotracheal tube was then passed into the trachea following the administration of suxamethonium chloride (I mg./kg., I.V.I.), and anaesthesia was maintained using a mixture of nitrous oxide and oxygen given by a closed circuit technique with the patient breathing spontaneously. In four patients halothane $\frac{1}{4-\frac{1}{2}}$ per cent, and in one methoxyflurane were used as supplementary anaesthetic agents.

When the effects of the initial dose of suxamethonium chloride and drug used to induce anaesthesia had worn off, the scalp potentials following the presentation of 120 tone bursts were recorded on an instrumentation tape recorder for subsequent analysis. A second series was recorded one minute after the administration of suxamethonium chloride (I mg. $/ \mathrm{kg}$., I.V.I.), or some time following d-tubocurarine hydrochloride $(0.6 \mathrm{mg} . / \mathrm{kg}$., I.V.I.) and gallamine triethiodide $(2-2.5 \mathrm{mg}$./kg., I.V.I.). The presence of muscle paralysis during this second series of recordings was also checked by observing the absence of spontaneous respiration. Following surgery three patients volunteered to have average evoked responses recorded in the awake state.

The acoustic signal which was presented to the patient was prerecorded on one channel of a Revox tape recorder. The sound had a frequency of $\mathrm{I} \cdot \mathrm{O} \mathrm{kHz}$, a duration of $50 \mathrm{~m} / \mathrm{sec}$. a rise and fall-time of $2.5 \mathrm{~m} / \mathrm{sec}$., an intensity of Ioo-II7 db. re 0.0002 dynes $/ \mathrm{cm}^{2}$, and was presented at a rate of $0.9 / \mathrm{sec}$. The voltage on the tape recorder was then fed to a pair of TDH 39 earphones through a matching transformer.

Analog signals from the patient were recorded differentially between the vertex and mastoid process using disc electrodes made of solder. The patient was also earthed at the wrist. The scalp potentials were amplified by a Grass PI 8 B microelectrode, D.C. amplifier (gain $\times$ Ioo, band pass, D.C. $-3 \cdot 0 \mathrm{kHz}$ ), and Tektronix I22 pre-amplifier (gain, $\times 1000$; band pass, $0 \cdot 2-250 \mathrm{~Hz}$ ). They were recorded on one channel of a HewlettPackard 3960 instrumention tape recorder, the other channel being used for a timing signal. The recorded potentials were fed into a HewlettPackard 5610A analog to digital converter, analyzed statistically by a Hewlett-Packard 2roo computer, and displayed on a Hewlett-Packard I300A X-Y display. During the analysis, the raw EEG signals were also displayed on a Telequipment S54AR cathode-ray oscilloscope.

In this paper latency measurements are all made from the onset of the stimulus to the peak of a wave.

\section{Results}

Auditory evoked potentials were recorded from the vertex of three out of the nine patients. In the remaining six, responses could not be recorded, and they were probably suppressed by the pre-medication and drugs used to induce the anaesthetic. 


\section{The effects of muscle relaxants on auditory evoked potentials}

Examples of the average responses obtained before and after the administration of a muscle relaxant can be seen in Figures $I$ and 2. In patient I (Fig. I $a$ ) an auditory evoked response with $\mathrm{N}_{1}, \mathrm{P}_{2}$ and $\mathrm{N}_{2}$ components was recorded after pre-medication with $70 \mathrm{mg}$. of pethidine

PATIENT 1

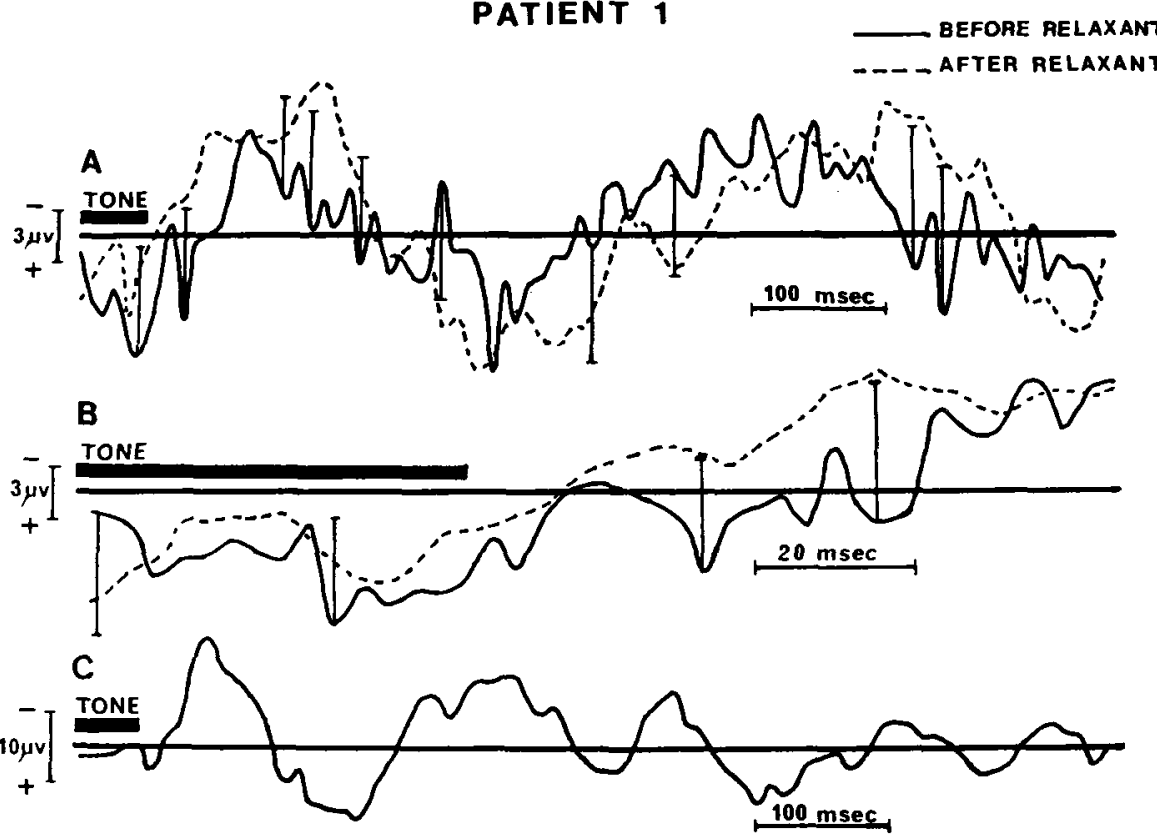

FIG. I.

Average auditory evoked responses from Patient I.

(A) The overall responses before and after the administration of a muscle relaxant (suxamethonium chloride).

(B) The short latency responses before and after the administration of a muscle relaxant. (C) The evoked response in the awake state.

A response above the base line refers to a potential which is negative at the vertex with respect to the mastoid eminence. The vertical bars represent two standard errors of the mean.

hydrochloride, and induction of the anaesthetic with $200 \mathrm{mg}$. of thiopentone sodium. A similar evoked response was then recorded after the administration of a muscle relaxant (suxamethonium chloride, $75 \mathrm{mg}$. I.V.I.). In patient 9 (Fig. $2 a$ ) a response with $\mathrm{NI}_{\mathrm{I}}$ and $\mathrm{N} 2$ components was recorded after pre-medication with $50 \mathrm{mg}$. of pethidine hydrochloride, and induction of the anaesthetic with $500 \mathrm{mg}$. of propanidid. A similar evoked response was recorded after the administration of a muscle relaxant (d-tubocurarine hydrochloride, $30 \mathrm{mg}$. I.V.I.). In patient 6 an NI response was obtained after pre-medication with $30 \mathrm{mg}$. of pethidine hydrochloride, and induction of the anaesthetic with $400 \mathrm{mg}$. of propanidid. A similar evoked response was recorded after the administration of a muscle relaxant (suxamethonium chloride, $75 \mathrm{mg}$. I.V.I.). 


\section{Field W. Rickards, et al.}

Differences between corresponding points on the average evoked response curves, recorded before and after the administration of a muscle relaxant, were considered not significant if they were less than twice the standard error of the difference for these points. This occurred for all points on the overall responses in patient I (Fig. I $a$ ), and patient 6 . In patient 9 (Fig. 2a) there was no significant difference between the responses

\section{PATIENT 9}

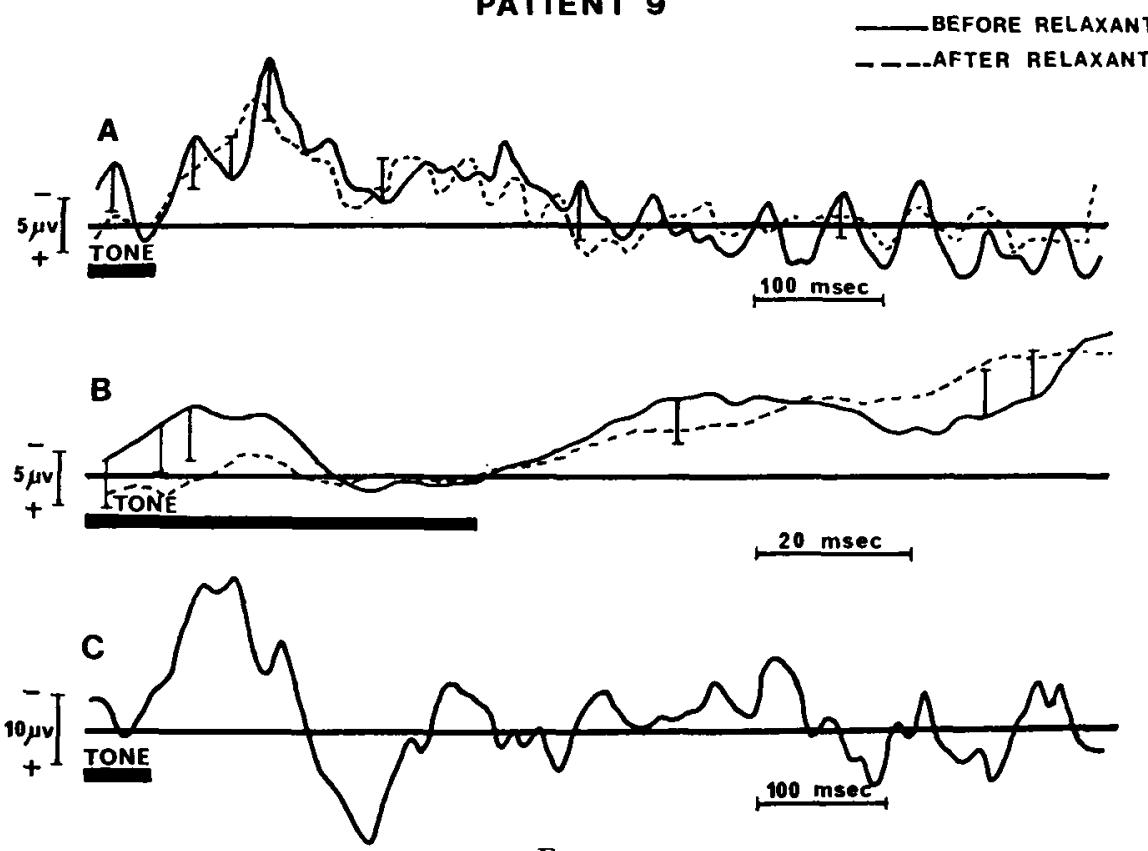

FIG. 2.

Average auditory evoked responses from Patient 9.

(A) The overall responses before and after the administration of a muscle relaxant (d-tubocurarine hydrochloride).

(B) The short latency responses before and after the administration of a muscle relaxant. (C) The evoked response in the awake state.

A response above the base line refers to a potential which is negative at the vertex with respect to the mastoid eminence. The vertical bars represent two standard errors of the difference.

for points with latencies greater than $30 \mathrm{~m} / \mathrm{sec}$. There appeared to be a difference, however, for a component which had a latency of $12 \mathrm{~m} / \mathrm{sec}$. from the onset of the stimulus to the peak of the wave. This component was significantly reduced following the administration of a muscle relaxant.

The evoked potentials in the first $100 \mathrm{~m} / \mathrm{sec}$. following the acoustic stimulus were also averaged separately to enable a more detailed analysis to be made, and to see what components with short latencies were reduced by the muscle relaxants. In patient $\mathbf{I}$ a small positive wave with a latency of $30 \mathrm{~m} / \mathrm{sec}$. was recorded, and this was not reduced by the muscle relaxant (Fig. Ib). In patient 6 no short latency response was detected. 


\section{The effects of muscle relaxants on auditory evoked potentials}

In patient 9 a monophasic negative wave with a latency of $\mathrm{I} 2 \mathrm{~m} / \mathrm{sec}$. was recorded, and this was reduced significantly by a muscle relaxant (Fig. 2b).

Auditory evoked responses were also recorded from patients I and 9 when they were awake. Patient I (Fig. Ic) had NI, $\mathrm{P}_{2}$ and N2 components, but these had shorter latencies than those obtained under anaesthesia. For example, the latencies of the $\mathrm{N}_{2}$ component were $306 \mathrm{~m} / \mathrm{sec}$. when awake, and $5 \mathrm{I} 6 \mathrm{~m} / \mathrm{sec}$. under anaesthesia. In patient 9 (Fig. $2 c$ ) there was much less difference in the latencies of the components recorded when awake and under anaesthesia. The main difference between the responses, however, was the marked reduction in the $\mathrm{P} 2$ component which occurred in the recordings made under anaesthesia.

\section{Discussion}

Many studies have reported changes in auditory evoked responses that are correlated with the sensory stimulus parameters, for example, Butler et al. (1969) have shown that the amplitude and area confined by the evoked potential increased with the intensity of the sound as a power function. These changes in the scalp potentials, however, do not necessarily indicate that they are neural in origin. More direct evidence has been obtained by Ruhm et al. (1967) and Celesia et al. (1968) who have shown that potentials recorded simultaneously from cortical and scalp electrodes are similar. Nevertheless, this did not apply to the PI and some longer latency components of the scalp potentials, and for this reason it was concluded that some components could be myogenic. It can also be argued that the similarities between the simultaneously recorded scalp and cortical responses were due to current flowing through the break in the tissues created by the neurosurgical operation.

Consequently, more direct evidence is desirable before it can be concluded that the auditory evoked potentials are not myogenic. It was shown by Bickford et al. (r964) that a short latency auditory evoked response $(6-8 \mathrm{~m} / \mathrm{sec}$.) was abolished by a muscle relaxant, and this is good evidence that this particular response is myogenic. There have not been other studies on patients, however, to indicate whether the components with latencies greater than $6-8 \mathrm{~m} / \mathrm{sec}$. are affected by muscle relaxants. This may be partly due to the fact that this cannot be readily carried out unless under anaesthesia, as subjects are otherwise not happy to volunteer for an unpleasant procedure. If it is performed under anaesthesia this creates further difficulties as many anaesthetic agents have been shown to reduce or abolish evoked responses (Abrahamian et al., I963; Davis et al., I957). Nevertheless, we have been able to record evoked responses by using a small dose of thiopentone sodium to induce the anaesthetic, and a mixture of nitrous oxide and oxygen to maintain this state. With further experience we have found it preferable to use propanidid as an inducing agent because it has a very short action and is 


\section{Field W. Rickards, et al.}

rapidly metabolized by the body. With this technique it has been possible to record auditory evoked responses from three out of nine patients. In these patients $\mathrm{N}_{1}, \mathrm{Pr}_{1}, \mathrm{~N}_{2}$ and $\mathrm{P}_{2}$ components were recorded before and after the administration of a muscle relaxant, so it can be concluded that they are not myogenic but probably neurogenic.

In this study the short latency response described by Bickford et al. (I964) could only be recorded in one out of three patients. As it has been shown that an increase in tension in the occipital muscles is necessary to elicit this response, our ability to record a short latency evoked potential in only one patient could be explained by the fact that on the operating table the occipital muscles were usually not under tension.

It is also of interest to examine the differences that occurred between the auditory evoked responses recorded in the awake state and under anaesthesia in patients $I$ and 9 . In patient I (Fig. I) the latencies of the components of the evoked response were greatly increased under anaesthesia. This was not the case, however, with patient 9 (Fig. 2) where the latencies were not appreciably affected. Patient $\mathrm{I}$ received thiopentone sodium and patient 9 propanidid, otherwise their anaesthetics were similar. Therefore, it seems likely that thiopentone sodium had an effect on the latency of the response. This is supported by the work of Ciganek (I96I), who showed that the latencies of visual evoked responses were increased by barbiturates.

In both patients the $\mathrm{P} 2$ component was reduced under anaesthesia, and as nitrous oxide was given in both cases the effect may have been due to this agent. This is supported by the fact that Lader and Norris (I969) showed that nitrous oxide had a marked effect on the positive component of an auditory evoked response which had a latency of $78-139 \mathrm{~m} / \mathrm{sec}$.

The effects of thiopentone sodium and nitrous oxide on various components of the evoked response have not been demonstrated on a sufficiently large number of patients in this study to be able to state that they have a selective effect on the response. The results are, however, of interest and warrant further investigation.

\section{Summary}

In this study it has been shown that in three out of nine patients auditory evoked responses with $\mathrm{N} r, \mathrm{P}_{1}, \mathrm{~N}_{2}$ and $\mathrm{P}_{2}$ components could be recorded under surgical anaesthesia. These responses were not reduced following the administration of a muscle relaxant. Therefore it was concluded that the evoked responses from these patients were not myogenic but probably neurogenic.

\section{Acknowledgements}

This study was performed on patients at The Royal Victorian Eye and Ear Hospital. We are grateful for the assistance provided by members 


\section{The effects of muscle relaxants on auditory evoked potentials}

of this hospital. We are indebted to Dr. G. Domaingue for administering most of the anaesthetics, and Mr. J. S. Maritz for statistical advice. We would like to thank Mr. R. J. Walkerden for his technical assistance and Mrs. C. J. Russell for the typing.

\section{REFERENCES}

Abrahamian, A. H., Allison, T., Goff, W. R., and Rosner, B. S. (1963) Anesthesiology, 24, 650 .

Bickford, R. G., Jacobson, J. L., and Cody, D. T. (1964) Annals of the New York Academy of Science, 112, 204.

Butler, R. A., Keidel, W. D., and Spreng, M. (1969) Acta oto-laryngologica, 68, $3 I 7$.

Celesia, G. G., Broughton, R. J., Rasmussen, T., and Branch, C. (I968) Electroencephalography and Clinical Neurophysiology, 24, 458.

CiganeK, L. (I96I) Electroencephalography and Clinical Neurophysiology, 13, 165.

Davis, H. S., Collins, W. F., Randt, C. T., and Dillon, W. H. (1957) Anesthesiology, 18, 634 .

Domino, E. F., and Corssen, G. (1964) Annals of the New York Academy of Science, $112,226$.

Lader, M., and Norris, H. (I969) Psychopharmacologica, 16, II 5.

Prichard, J. W., Chimienti, J., and Galambos, R. (1965) Electroencephalography and Clinical Neurophysiology, 18, 493.

Ruhm, H., Walker, E., and Flanigin, H. (1967) Laryngoscope, 77, 806.

Please address all correspondence to:

Graeme M. Clark,

Department of Otolaryngology,

University of Melbourne,

Royal Victorian Eye and Ear Hospital,

East Melbourne 3002,

Australia. 


\section{University Library}

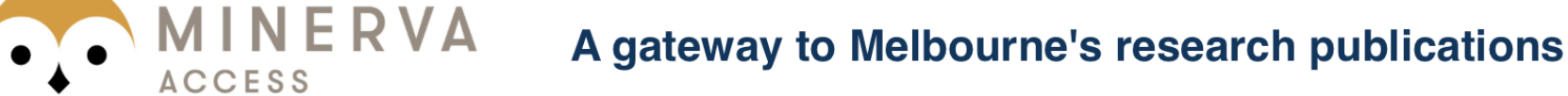

Minerva Access is the Institutional Repository of The University of Melbourne

Author/s:

Rickards, Field W.;Clark, Graeme M.;McMahon, Don S.;Dewhurst, David J.

Title:

The effects of muscle relaxants on auditory evoked potentials in humans

Date:

1973

Citation:

Rickards, F. W., Clark, G. M., McMahon, D. S. \& Dewhurst, D. J. (1973). The effects of muscle relaxants on auditory evoked potentials in humans. Journal of Laryngology and Otology, 87(7), 647-653.

Persistent Link:

http://hdl.handle.net/11343/27146 